\title{
Revisiting Kuo and Belland's exploratory study of undergraduate students' perceptions of online learning: minority students in continuing education
}

\author{
Beth Beschorner ${ }^{1}$ (D)
}

Accepted: 10 November 2020 / Published online: 19 November 2020

(c) Association for Educational Communications and Technology 2020

\begin{abstract}
COVID-19 has forced educators to make rapid changes to their pedagogy in order to shift from face-to-face instruction to online delivery. In this time of rapid change, Kuo and Belland's (Educ Technol Res Dev 64:661-680, 2016) exploratory study that highlights the types of interactions that correlated with African American students' success in an undergraduate course could provide instructors with ideas about how to create more equitable online courses. Thus, this article describes how instructors might consider the cultural and racialized experiences of their students through an asset lens as they design online coursework. Specifically, instructors should attend to students' experiences and determine how students will interact with the content, with the instructor, and with other learners. Implications are described.
\end{abstract}

Keywords Online interactions · Online teaching · Online learning · Equitable online instruction

\section{Introduction}

COVID-19 has forced educators from around the world to fundamentally change their pedagogy, because they have been forced to rapidly pivot their instruction from face-to-face instruction to online delivery. This shift has been difficult for many educators and has highlighted, and in some cases magnified, the inequities that exist around the world between different cultures, racial groups, economic classes, etc. These inequities include access to technology, access to reliable Internet, etc. Kuo and Belland's (2016) exploratory study of African American undergraduate students' perceptions of online learning provides important insights for educators that aim to create more equitable online courses in this time of rapid change by highlighting the types of interactions that correlate with student success. This study is important given its focus on African American students, a historically underserved and minoritized population in the United States but may also have implications for

Beth Beschorner

Beth.beschorner@mnsu.edu

1 Minnesota State University, Mankato, MN, USA 
other people of color who might share similar marginalizing experiences. Thus, the purpose of this article is to describe how Kuo and Belland's (2016) findings might influence course design that encourages African American students', and, perhaps, other people of color's, academic success.

\section{Interactions in an online course: practical implications}

The interaction framework (Moore 1989) that undergirds Kou and Belland's (2016) study is of particular utility in current times, because as instructors shift their courses online, perhaps for the first time, they should be considering the ways that students are interacting in their course. As instructors are making these decisions, instructors should consider how students' racialized experiences, culture, and languages and dialects will contribute to the ways that students interact with each other and with the content. That is, instructors much ensure that their online courses are not built on standards of whiteness, but rather build on the unique linguistic and cultural assets that students bring to the course. African American students and other students of color can add multiple racial perspectives to online discussions and instructors should view their contributions as an asset to the course.

In Kou and Belland's (2016) study, learner-instructor and learner-content interactions seemed to be particularly important to learner satisfaction. Learner-content interaction was the highest predictor of student satisfaction and this is important, given that student satisfaction was correlated to student success. However, all three types of interaction were significant. Thus, careful course design is critical. As instructors design their courses, they should give careful attention to using what they know about their students to intentionally determine how learners will interact with the content, with the instructor, and with other learners.

\section{Interactions with the content}

Kuo and Belland's (2016) results suggest that learner-content interactions were particularly significant to students' satisfaction and success within the course. Some of the following questions from the Technology Integration Planning Cycle might be useful as instructors design the content of their courses with attention to how students will interact with the content in the online course: (1) What is the goal of learner-content interaction? (2) What instructional approach(es) (e.g. video lecture, reading assignment, group project, etc.) would effectively work toward this goal? (3) What digital tools and digital content could support and contribute to this goal? (4) What will the constraints be and how can they be overcome? (Hutchison and Woodward 2014). Moreover, as instructors make these decisions, they should also consider the racialized and gendered perspectives that are present (or not) in the content to ensure that multiple perspectives are represented. That is, African American students and other students of color should be able to see their own experiences and communities represented in the curriculum.

\section{Interactions with the instructor}

The quality of all students' relationships with faculty is significant for student learning but it is particularly significant for students who are African American (Lundberg and Schreiner 2004). Therefore, the importance of developing learner-instructor relationships, 
particularly in an online environment, where the development of relationships must be intentional, and with African American students and other students of color, cannot be understated. When designing online instruction, instructors should consider how they will interact with students in multiple ways. For example, instructors might consider interacting with students through recording introductions to new content, capturing video lectures, responding to students' discussions, providing feedback, etc. As these and other approaches are being considered, it is important to note that the quality of interactions seems to be more important to students than the quantity of interactions (Swan 2002).

\section{Interactions with other learners}

There are many ways that students can collaborate with one another online (e.g. synchronous video meetings, asynchronous discussion boards, group projects, etc.). This collaboration should be designed intentionally with careful attention to misunderstandings that can arise between students with different racial and cultural backgrounds, especially in online spaces like discussion boards (McKee 2002). It is possible that it might be prudent for instructors to use modeling to avoid misunderstandings. It may be useful to use protocols, like the Courageous Conversations About Race protocol (Singleton 2014) for some course content. Further, instructors should give consideration to their content area and the students' background knowledge as they plan opportunities for learner-learner interaction. Interestingly, less might mean more, since Kuo and Belland (2016) found that learnerlearner interactions actually decreased with more discussion forums.

\section{Internet self-efficacy}

The greater a student's Internet self-efficacy, the more students perceive to interact with the content, their instructors, and other learners (Kuo and Belland 2016) and the stronger the student's academic performance (Bradley et al. 2017). Therefore, institutional leaders may want to consider taking measures to ensure all students are supported in developing Internet self-efficacy during this time. This is particularly important for students of color, since Internet usage, particularly for academic purposes, varies by race (Jones et al. 2009).

\section{Limitations}

There are some limitations of Kuo and Belland's (2016) study for instructors shifting to online delivery of courses. For example, differences in experiences for students who speak multiple languages were not explored. Further, this study addressed one content area and it is possible that interactions might change in different types of courses (e.g. different types content areas, courses within or outside an interest area, etc.).

\section{Compliance with ethical standards}

Conflict of interest The author declares that she has no conflicts of interest.

Ethical approval No research was conducted with human participants and/or animals. 


\section{References}

Bradley, R., Browne, B., \& Kelley, H. (2017). Examining the influence of self-efficacy and self-regulation in online learning. College Student Journal, 51(4), 518-530.

Hutchison, A., \& Woodward, L. (2014). A planning cycle for integrating digital technology into literacy instruction. The Reading Teacher, 67(6), 455-464. https://doi.org/10.1002/trtr.1225.

Jones, S., Johnson-Yale, C., \& Millermaier, S. (2009). U.S. college students' Internet use: Race, gender, and digital divides. Journal of Computer-Mediated Communication, 14, 244-264. https://doi.org/10.111 1/j.1083-6101.2009.01439.x.

Kuo, Y., \& Belland, B. R. (2016). An exploratory study of adult learners' perceptions of online learning: Minority students in continuing education. Educational Technology Research and Development, 64, 661-680. https://doi.org/10.1007/s11423-016-9442-9.

Lundberg, C., \& Schreiner, L. (2004). Quality and frequency of faculty-student interaction as predictors of learning: An analysis by student race/ethnicity. Journal of College Student Development, 45(5), 549565. https://doi.org/10.1353/csd.2004.0061.

McKee, H. (2002). "YOUR VIEWS SHOWED TRUE IGNORANCE!!!”: (Mis)communication in an online interracial discussion forum. Computers and Composition, 19(4), 411-434. https://doi.org/10.1016/ S8755-4615(02)00143-3.

Moore, M. G. (1989). Editorial: Three types of interaction. American Journal of Distance Education, 3(2), 1-7. https://doi.org/10.1080/08923648909526659.

Singleton, G. (2014). Courageous conversations about race: A field guide for achieving equity in schools. New York: Corwin.

Swan, K. (2002). Building learning communities in online courses: The importance of interaction. Education, Communication, \& Information, 2(1), 23-49. https://doi.org/10.1080/1463631022000005016.

Publisher's Note Springer Nature remains neutral with regard to jurisdictional claims in published maps and institutional affiliations.

Beth Beschorner is an Associate Professor and Department Chair of the Department Elementary and Literacy Education at Minnesota State University, Mankato. She teaches graduate courses in literacy, technology, and scholarly writing. Her research interests include literacy, technology, and issues related to race, racism, and anti-racism. Her work has been published in journals such as The Reading Teacher, The International Journal of Education in Mathematics, Science, and Technology, and Technology, Pedagogy, and Education. 